\title{
Information Processing for Learning Systems: an Action Theoretical Approach
}

\author{
Matthias Rauterberg and Eberhard Ulich \\ Work and Organisation Psychology Unit (IfAP) \\ Swiss Federal Institute of Technology (ETH) \\ Nelkenstrasse 11, CH-8092 ZUERICH, Switzerland \\ +41-1-632 70 82, rauterberg@ifap.bepr.ethz.ch
}

\begin{abstract}
Information and information processing are one of the most important aspects of dynamic systems. The term 'information', that is used in various contexts, might better be replaced with one that incorporates novelty, activity and learning. Many important communications of learning systems are non-ergodic. The ergodicity assumption in Shannon's communication theory restricts his and all related concepts to systems that can not learn. For learning systems that interact with their environments, the more primitive concept of 'variety' will have to be used, instead of probability. Humans have a fundamental need for variety: He can't permanently perceive the same context, he can't do always the same things! Following an action theoretical approach we have to conclude a fundamental need for variety. This need for variety leads to a different interpretation of human behavior that is often classified as "errors". Variety is the basis to measure complexity of an activity. Complexity in the relationship between a learning system and his context can be expressed as incongruity. Incongruity is the difference between internal complexity of a learning system and the complexity of the context. Traditional concepts of information processing are models of homeostasis on a basic level withou learning. Activity and the irreversible learning process are driving forces that cause permanently in-homeostasis in the relationship between a learning system and his context. A suitable model for information processing of learning systems must be conceptualised on a higher level: a homeostatic model of 'in-homeostasis'. A concept to information processing is presented that derives an inverted U-shaped function between incongruity and information. This concept leads to some design recommendations for man-machine systems.
\end{abstract}

\section{INTRODUCTION}

We can find in the literature different interpretations of the term 'information'. Several approaches from different point of views are done to clarify 'information' (see [Rauterberg 1995a], [Topsøe 1974], [Völz 1991] [Kornwachs 1996]): (1) information as a message (syntax); (2) information as the meaning of a message (semantic); (3) information as the effect of a message (pragmatic); (4) information as a process; (5) information as knowledge; (6) information as an entity of the world.

Table 1. Several terms to describe the amount of information of a message before and after reception.

\begin{tabular}{lll}
\hline before reception & after reception & Author \\
\hline $\begin{array}{l}\text { degree of freedom } \\
\text { of the decision }\end{array}$ & $\begin{array}{l}\text { content of the } \\
\text { decision }\end{array}$ & HARTLEY 1928 \\
$\begin{array}{l}\text { uncertainty } \\
\text { uncertainty }\end{array}$ & $\begin{array}{l}\text { certainty } \\
\text { information }\end{array}$ & SHANNON 1949 \\
$\begin{array}{l}\text { potential information } \\
\text { entropy }\end{array}$ & actual information & BRILLOUIN 1964 \\
& ZUCKER 1974 \\
\hline
\end{tabular}

If we try to apply information theory to human behavior, then we have to integrate activity, perception, and learning. In this proposal we are looking for an interpretation of 'information', which is compatible with concepts of activity and learning. Going this way, we hope to avoid the paradox of 'new' information. Information before and after the reception of a message is not the same! Different concepts are introduced in the literature to 'solve' this paradox (see Table 1).

\section{ACTIVITY AND PERCEPTION}

Neisser [Neisser 1976] was one of the first researcher, who tried to integrate activity, perception, and learning. He emphasised that human experience depends on the stored mental schemata, which guide explorative behavior and the perception of an external context. Learning increases constantly the complexity of the mental model (especially the structure of the cognitive knowledge base). This is an irreversible process [Bateson 1972]. One consequence of this irreversibility is, that the contextual complexity must increase appropriately to fit the human's needs for optimal variety and stimulation.

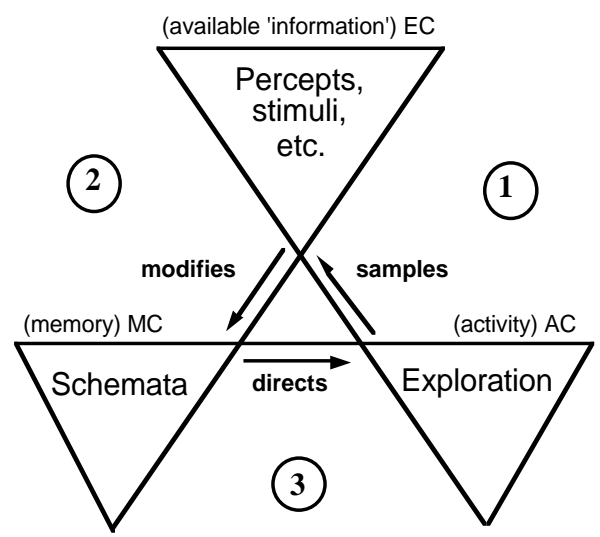

Figure 1. The complete perceptual cycle [Neisser 1976].

If we take this concept into serious considerations, then we can identify several open questions: How is activity coupled with the perception of the external world (the context; see point 1 in Figure 1)? How does perception depend on the internal mental schemata (see point 2 in Figure 1)? What is 'available information'? How do the mental schemata direct actions, and how they are modified by the perceived range of available information (see point 3 in Figure 1)?

In this paper we can show how it could be possible to come up with answers to these questions: (1) to analyse the complexity of observable actions we present and 
discuss a straight forward approach (point 1 [Rauterberg 1993]); (2) to analyse the complexity of perception we discuss the outcome of an empirical study (point 2); and, (3) to explain how the schemata direct behavior we introduce the Action Theory (point 3 [Hacker 1994]).

\section{WHAT IS HUMAN ACTIVITY?}

Leontyev's three-level schema ([Leontyev 1978], see Figure 2) describes the sphere of analysis and directs the attention to the transformations going on between three levels: motive-activity, goal-action, and instrumental conditions-operations [Engeström 1991]. These three levels are organised in a hierarchical structure where the top level of activities includes several actions that are performed by appropriate operations. In a 'pure' objective way only the operational level can be observed and analysed. The goal setting and motivational level must be derived or investigated by indirect methods (e.g., questionnaire, interview, thinking aloud, etc.) based on the introspective observations of the investigated subjects. (Note the similarity to the model in [Rasmussen 1986]: knowledge based, rule based, and skill based level.)

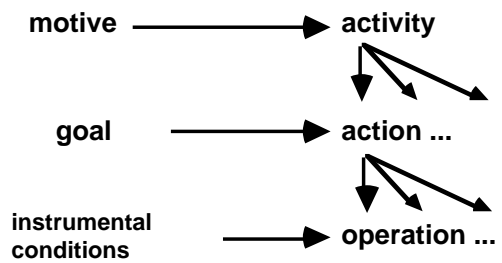

Figure 2. The three levels schema of the activity theory of [Leontyev 1978].

Action regulation theory offers a coherent body of principles for human-centered task and work design [Hacker 1994]. For Hacker ([Hacker 1986], p. 61), the work order, its interpretation or its acceptance as a work task is "the central category of psychological consideration of activity..., as decisive specifications for the regulation and organisation of the activities occur with the 'objective logic' of its contents". This quotation makes clear that for all, who follow the activity or action theory, the task becomes very important in the analysis of behavior. Great importance is attached to the concept of the complete task.

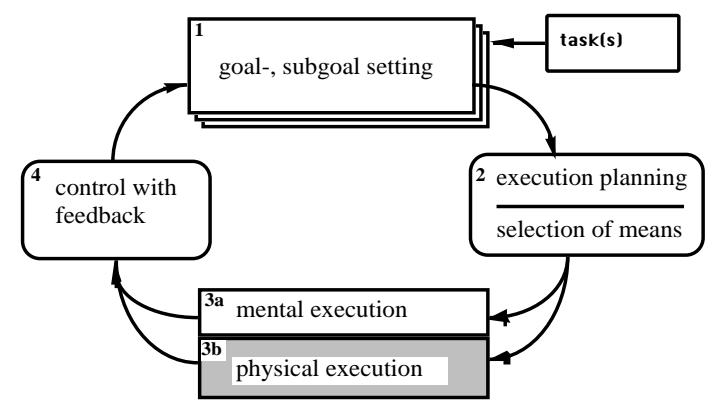

Figure 3. The complete action-cycle: the central concept of the action regulation theory [Hacker 1994].

Hellpach ([Hellpach 1922], p. 27) described the task concept as follows: "A task consists of one's own planning and design--if not design of the task, design of its solution, including choice between various possibilities, decision for one of these, taking responsibility for the decision, the ways of performance, while completing the task the constant, infinitesimal evaluation of success related to the mentally represented goal, and finally, the belief that it was well done". Hellpach's description already included the main elements of the concept of the complete task as defined by Tomaszewski ([Tomaszewski 1981], p. 23): "A complete task contains three basic elements: diagnosis of the starting situation, outline (project) of a new situation and a program of realizing activities. During the course of the task performance, these three elements are supplemented by a continuous diagnosis of the changing situation". These are the basic constituents of Hacker's concept of complete activity [Hacker 1986].

Characteristics of complete tasks, which must be taken into consideration when analysing and/or designing human activities (e.g., job design), are, according to the concept of action regulation theory presented here (see Figure 3, and [Ulich 1991]):

(1) Independent setting of goals which are embedded in the superimposed goals;

(2) Independent action preparation in the sense of taking on planning functions; and, selection of the means including the necessary interaction for goal attainment;

(3) Mental or physical performance functions with feedback on performance pertaining to possible corrections of actions;

(4) Control with feedback on results and the possibility of checking the results of one's own actions against the set goals.

Incomplete activities--or partialized actions--"lack, to a large extent, possibilities for independent goal-setting and decision-making, for developing individual work styles or sufficiently precise feedback" ([Hacker 1987], p. 35). Complete activities (or tasks) offer the possibility of setting goals and sub-goals, as well as of offering decision-making possibilities during the various phases of task completion, and therefore provide latitude of activity or action. Complete activities are therefore becoming fundamental for realising the concept of action regulation. Goals are organised in a hierarchical tree structure [Hacker 1986]. The complete action cycle (see Figure 3) has a fractal or recursive structure: Each component of the complete action cycle can be analysed with an embedded and subordinated action cycle. Chunking occurs over Leonteyev's all three levels (see Figure 4).

"Action Theory seems to be an integrative long-term approach that is still developing especially with the development of hierarchically subordinate sub approaches. Action Theory is still more a heuristic broad-range framework than a final theory. ... The integrative power of Action Theory will bridge some interrelated gaps: the gap between cognition (and knowledge) and action, the gap between cognition and motivation (see goal orientation), and even the gap between basic and more applied approaches ..." ([Hacker 1994], p. 113).

Our main research interest is bridging both gaps. (ad 1) The sum of all cognitions are determined by the mental knowledge. Learning is a permanent process that is regulated by optimising the external complexity based on actions. (ad 2) An self regulated system maximise his information processing by optimising the situational incongruity. 


\section{WHAT IS A LEARNING SYSTEM?}

The brain is the operating system for human cognitions. One part--probably the most important part--of a human brain is the memory with all stored and strictly organised knowledge. But, there very few learning theories that can describe and explain metalearning phenomenons (e.g., learning from experience) [Weinert 1984] [Tuijnman 1992]. One of the most powerful concept was introduced by Gregory Bateson [Bateson 1972].

Bateson developed the concept of "deutero learning" to describe metalearning phenomenons ("learning to learn" [Bateson 1972]). The basic idea of this concept is that the variety on one level can be reduced to its invariant structure. This invariant structure forms the next higher, more abstract level of learning. Deutero learning can appear on five different hierarchical levels:

Level-0: The perception of a specific situation leads directly to a specific reaction. Learning on the level means that a system shows different activities in dependency of the perceived situational context; no correction or change in the same situation can be observed. This deutero learning type is possible for all living systems.

Level-1: Dependent on the assessment of the outcome adaptive behavior can be observed in a given set of alternative actions; after erroneous behavior corrections are possible by selecting an alternative action. The system learns to choose the correct element in a given set of elements. Level-1 deutero learning includes habituation, classical conditioning, extinction, etc..

Level-2: Learning on this level includes two types of adaptive behavior: first, selecting the correct set of actions in a given meta-set of sets of actions, and second, interpreting the own learning history in a different way. The sum of all deutero learning on level- 2 is often described in concepts like personality, character, etc..

Level-3: If a living system changes (reorganises, resp.) its internal structure in a fundamental way then a level-3 deutero learning process took place. Level-3 deutero learning includes a conscious way of changing the own personality (e.g., psycho therapy).

Level-4: Learning on this level means adaptive behavior on an ontological or genetic level. This level is not controllabel by an individuum.

If we look from a very general perspective on living systems (e.g., individuals, groups, organisations, etc.), we can compare all these different systems from an abstract learn theoretical view. Each learning system must have: (1) the possibility to plan actions and to execute them, (2) a storage (e.g., individual memory, shared group memory, anecdotes, etc.), (3) the possibility to evaluate the own behavior with excess to the storage, and (4) the possibility to include the assessment into the future action planning and execution (see Figure 4).

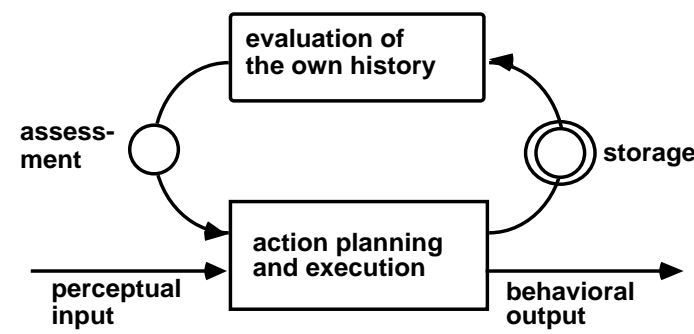

Figure 4. The different components of a learning system
We discuss learning of individual humans: One important difference between beginners and experts is the complexity of their mental model [Bainbridge 1991]. The beginners have a simple mental structure, so they have to behave in a more heuristic manner to behave in an unknown context. On the other hand, the structures of the mental model of the experts are more or less correct representations of the context structure, so they can behave efficiently to reach their goals. We therefore assume that the mental model of an expert is more comprehensive than that of a beginner. This assumption can be tested by comparing the complexity of the observable processes of beginners and experts.

The empirical results in [Rauterberg 1993] indicate, that the complexity (AC, see Figure 1) of the observable processes of beginners is larger than the complexity of experts. Therefore we concluded that the behavioral complexity is negatively correlated with the complexity of the underlying mental model (MC, see Figure 1). Thus it is possible to estimate the cognitive complexity based on the measurement of the behavioral complexity and based on the measurement of the contextual (environmental, resp.) complexity (EC, see Figure 1) [Rauterberg 1992].

Reviewing several articles about complexity in different research fields we found two dimensions of complexity [Flückiger 1995]: breadth and depth complexity. The breadth complexity is the most common interpretation (e.g., number of elements). An often neglected problem of breadth complexity is the underlying assumption that all elements have a similar amount of complexity of the internal structure (e.g., semantic). The solution to this problem is depth complexity: to measure the complexity of the internal structure. In the context of learning, chunking is the central process to build elements with increased depth complexity. All chunked knowledge is the corpus of individual experiences. To describe and to compare concrete task solving behavior on the same complexity level we have to observe these processes on the lowest possible level: the operations (see Figure 2).

\section{HOW TO MEASURE BEHAVIORAL COMPLEXITY}

Following the action theoretical framework we are able to analyse the continuously recorded stream of the observable operations. In the context of human-computer interaction this can be done very easily by the logfile recording technique [Rauterberg 1993]. What is the main concern of a user interacting with a technical system? The user must build up a mental representation of the system's structure and gain knowledge about the task relevant functions of this system. Furthermore, he must learn the "language", i.e., a set of symbols, their syntax, and operations connected to them, to evoke action sequences (the inter-active "processes") related to task and sub-task functions (goal and subgoal settings, resp.).

Given a finite action space, each state corresponds to a system context, and each transition from one state to another corresponds to a human operation. A trace (= sequence) of states and operations (i.e., transitions) in this action space describes a complete (or partial) task solving process. Each finite trace in the action space is called a "process". Each task solving process contains 
three different kinds of information: (1) all necessary states and operations itself, (2) the amount of repetition of each state and operation, and (3) the sequential order of all these states and operations.

Finite state transition nets can be completely described with Petri nets, which have a clear semantic [Peterson 1981]. A Petri net is a mathematical structure consisting of two non-empty disjoint sets of nodes, called S-elements and T-elements, respectively, and a binary relation $\mathrm{F}$, called the flow relation. $\mathrm{F}$ connects only nodes of different types and leaves no node isolated. Petri nets can be interpreted by using a suitable pair of concepts for the sets S (signified by a circle "( )") and T (signified by a square "[ ]") and a suitable interpretation for the flow relation $\mathrm{F}$ (signified by an arrow "->"). The means/activity interpretation allows one to describe the static structure of a system with several active and passive functional components: means $(S)=$ real or informational entity, and transitions $[\mathrm{T}]=($ repeatable $)$ operations (actions, resp.). The flow relation F signifies: [o] $\rightarrow(\mathrm{m})$, the operation 'o' (e.g., a user command) produces means 'm' (e.g., a system state); (m) -> [o], operation 'o' uses means ' $m$ '.

The main relations between two different nets or processes are abstraction, embedding and folding [Genrich 1980]. The 'folding' relation is the basic idea of our approach [Rauterberg 1993]. Folding a process means to map S-elements onto S-elements and T-elements onto T-elements while keeping the F-structure. The aim of the 'folding' relation is to reduce the elements of an observed empirical task solving process to the minimum number of states and transitions. This reduced number of elements can be interpreted as the performance net. Folding a sequential task solving process extracts the embedded net structure and neglects the information of the amount of repetition and of the sequential order. This 'extracted' and generated Petri net is the minimal net to reproduce the observed process [Rauterberg 1995b]. We interpret this 'folded' Petri net as a structural description of a complete task solving process.

To measure the complexity of an extracted net, we introduce the Ccycle metrics of McCabe (the "cyclomatic number" [McCabe 1976]) [Rauterberg 1992]. Ccycle is a measure to calculate the number of linear independent cycles of a plane and coherent net. Ccycle is a useful quantity that measures the amount of interconnectivity (i.e., complexity). The advantages and disadvantages of four different quantitative measures of complexity have been discussed in [Rauterberg 1992]; Ccycle proved to be the most effective measure.

Given a folded Petri net, the complexity measured with Ccycle is defined by the difference of the total number of connections (\#F: flow relation) and the sum of the total number of states and of transitions (\#S: state + \#T: transitions). The parameter $\mathrm{P}$ is a constant that corrects the result of Formula 1 in the case of a sequence $(\# \mathrm{~F}-$ $(\# \mathrm{~S}+\# \mathrm{~T})=-1)$; the value of $\mathrm{P}$ in this context is 1 . The semantic of Ccycle can be described by the number of "holes", "loops", "cycles" or "independent decisions".

"Cyclomatic number":

Ccycle $:=\# \mathrm{~F}-(\# \mathrm{~S}+\# \mathrm{~T})+\mathrm{P} \quad$ with $\mathrm{P}=1$

But, what can we do with this kind of metric?

\section{ACTIVITY AND INCONGRUITY}

Weizsäcker [Weizsäcker 1974] distinguished in his concept of 'information' between two dimensions: (1.) 'Singularity of the first time', and (2.) confirmation and redundancy. For both aspects we can find two different research traditions in psychology: (1) novelty and curiosity ([Berlyne 1960], [Hunt 1963], [Voss 1981]), and (2) dissonance theory ([Festinger 1957], [Frey 1981]). Both research tracks are only loose coupled till today.

Investigators of novelty assume, that living systems (like mammals, especially humans) are motivated by an information seeking behavior. In situations, which are characterized by sensory deprivation, mammals and humans are intrinsically looking for stimulation. They increase the complexity of the context or the perception of it. On the other side, mammals try to avoid situations with a high amount of stimulation, dissonance, or stress. Hunt [Hunt 1963] designated this amount of increased complexity as 'incongruity'.

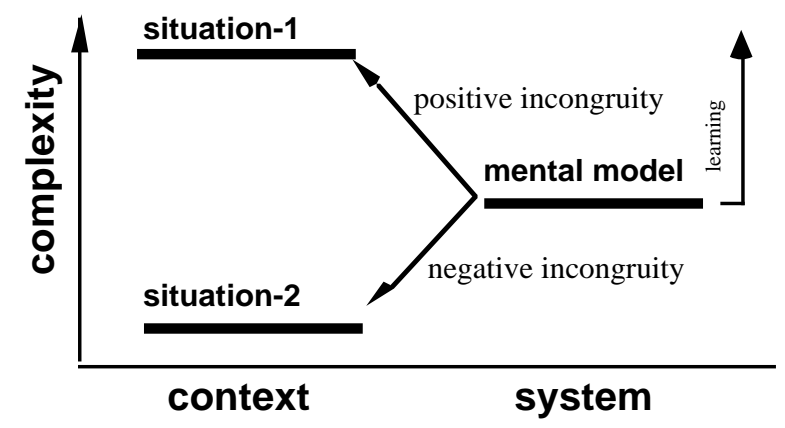

Figure 5. The difference between the complexity of the mental model (MC) and the complexity of the external context (EC) is called incongruity: $\mathrm{IC}=\mathrm{EC}-\mathrm{MC}$.

If the complexity of the mental model (MC) is less complex than the complexity of the context (EC), then mammals try to optimise this positive incongruity. Seeking behavior starts, when the positive incongruity (IC) sinks below an individual threshold or changes to negative incongruity (deprivation, see Figure 5). Behavior of avoidance can be observed, when the positive incongruity exceeds an individual threshold (dissonance, stimulation overflow). Most of daily situations can be characterized by positive incongruity.

The central question--but till now unsolved--question is the relationship between EC on one side and $\mathrm{AC}$ and $\mathrm{MC}$ on the other side. With the "cyclomatic number" Ccycle we are able to measure AC [Rauterberg 1993]. But, how does the perceived external complexity depend on the human's activity and mental schemata? We assume that EC must be a function of $\mathrm{AC}$ and MC: $\mathrm{EC}=\operatorname{pf}(\mathrm{MC}, \mathrm{AC})$. This unknown function pf must contain the full potential of perception of the contextual pattern complexity (e.g., the semantic of a situation with distinguishable elements).

As a first step to answer the question 'how to measure EC' we carried out an empirical investigation.

\section{PERCEPTION AND COMPLEXITY}

The modern discussion of information and complexity in the context of physics (cf. [Zurek 1991]) is based on the following paradox: Nearly all measures of informa 
tion increase monotonously with complexity of the stimulus pattern [Grassberger 1986]. But, the subjective impression of each observer is that a medium amount of entropy in contextual patterns contains the maximum of information, and not the pattern with zero or with the maximum of entropy! There must be an inverted Ushaped function between subjective 'information' and the information measured by entropy or complexity. The approaches of the physicists to overcome this paradox seem to be not convincing, because most researchers in this community are constrained by their implicit goal to look for an observer independent solution [Crutchfield 1991].

Therefore we have to look for an observer dependent measure for the complexity of a perceived context. This problem is difficult, because we have to differentiate between the pre-structured part of perception based on learned mental schemata (available information, see Figure 1) and the unstructured and not predictable part. Only the existence of unknown, but perceivable pattern enable us to integrate new aspects into our stored knowledge (potential available information, see [Rauterberg 1995a]).

An inquiry has been carried out to pinpoint the perceivable and actually perceived complexity of multimedia screens (see [Rauterberg 1995c]). The perceivable complexity is strongly influenced by the number of objects-and their relations to each other--on the screen. But, what is a "visually distinguishable object"?

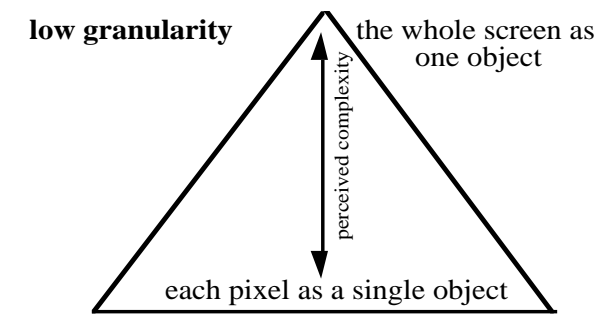

high granularity

Figure 6. The possible range of perceivable complexity (i.e., the external complexity EC) caused by the level of granularity.

To find out on which level of granularity visual pattern are classified as single "objects" (see Figure 6), a questionnaire with eight different screen-dumps of a commercial multimedia information system (called "mockups", see[Rauterberg 1995c]) was answered by a heterogeneous group of potential users. A total of 33 women (between 14 and 66 year of life) and 33 men (between 21 and 55 year of life) participated (no significant difference in age between both groups). The computer experience of each subject was measured on a rating scale ("no experience" $=0 \ldots$ "expert" = 90). We found a significant difference in computer experience between both groups: $40 \pm 27$ for women, and $63 \pm 24$ for men $(\mathrm{p} \leq .001)$; the men were more experienced than the women.

To measure the granularity level subjects were instructed to answer a "simple" question: Estimate the number of different perceived object on the screendump! The range of the estimated granularity lies between 2 and 35 perceived objects for women and between 3 and $30 \mathrm{ob}-$ jects for men. We can find a significant difference between both groups $(\mathrm{X}$ women $=9.9 \pm 6.3$ objects, $\mathrm{Xmen}=$
$12.0 \pm 6.1$ objects,$T$-test, $\mathrm{p} \leq .033$ ). The more experienced men estimated more distinguishable objects than the less experienced women. From this result we can conclude that the complexity of the knowledge structure (MC, see Figure 1) correlates positively with the perceived external complexity (EC).

Now, the last question to understand the equation $\mathrm{EC}=$ $\mathrm{pf}(\mathrm{MC}, \mathrm{AC})$ is the relationship between $\mathrm{EC}$ and $\mathrm{AC}$ ?

\section{ACTIVITY AND INFORMATION}

A context with sensory deprivation has not enough positive incongruity (IC, see Figure 5) or even negative incongruity [Smith 1981]. On one side, a human will leave a context with very low incongruity (to little difference to context complexity; see Figure 7), and on the other side with very high incongruity (to much context complexity, stimulation stress, resp.; see Figure 7). In between we have the range of positive emotions with behavior, that increase novelty on one side [Berlyne 1960], and on the other side that increase confirmation and redundancy, or reduce dissonance, resp. [Festinger 1957].

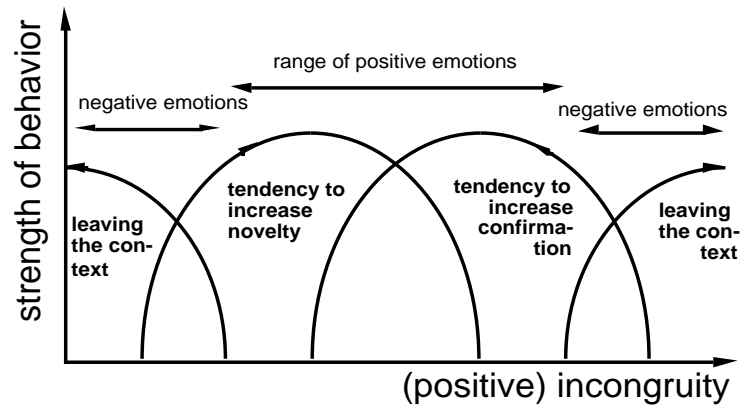

Figure 7. The coherence between positive incongruity, emotions and observable behavior (see [Rauterberg 1995a]).

Overall we assume a reverse u-curve as the summarised coherence between incongruity and information (see Figure 8, cf. [Yerkes 1908] [Streufert 1978]). If a human has to behave for a while in a total fixed and stabile context and he has a normal learning rate, then he must start incongruity increasing actions [Berlyne 1960]. This can be done on two different ways: (1) increasing the complexity of the context (the perception of it, resp.), and/or (2) reducing the complexity of the mental model. Way (2) implies the possibility of "forgetting" (decrease learning rate) or the manipulation of the perception mechanisms (suppression) (cf. [Rauterberg 1995a]).

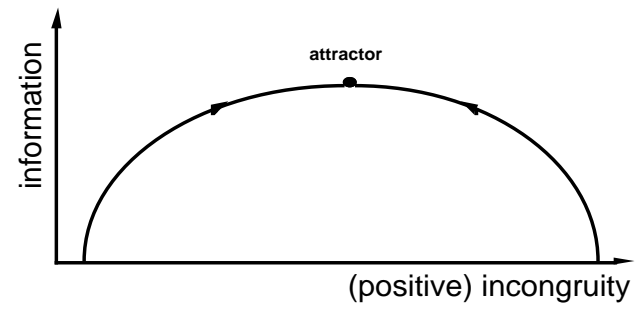

Figure 8. The summarised coherence between positive incongruity and information (see [Rauterberg 1995a]).

Now we are able to give a preliminary answer to the relationship between the perceived external complexity $\mathrm{EC}$ and the activity complexity AC: It depends on the 
actual amount of the incongruity IC! If IC is greater than an individual threshold then we will find a negative correlation between EC and AC. On the other side, if IC is less than an individual threshold then we predict a positive correlation between EC and AC (see Figure 9).

$$
\text { IC } \leq \text { indiv.minimum }
$$

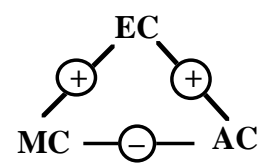

\section{IC $\geq$ indiv.maximum}

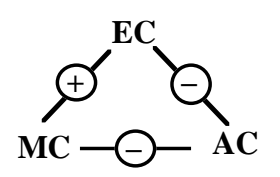

Figure 9 The two different situations to estimate $\mathrm{EC}$ in dependency of $\mathrm{MC}$ and $\mathrm{AC}$; with $\mathrm{IC}=\mathrm{EC}$ minus MC. [(+) := positive correlation, (-) $:=$ negative correlation]

Finally we can conclude that it could be possible to measure "information" in an observer dependent way. The actual processed amount of information can be exactly the same for totally different learning systems in very different learning stages: It depends on the complexity of the internal knowledge, the systems activities, and the perceivable action space in the actual learning environment. The most critical factor is the learning rate of the system (see Figure 5)!

\section{REFERENCES}

BAInBridge, L. (1991) The "cognitive" in cognitive ergonomics. Le Travail humain 54: 337-343.

BAtESON, G. (1972) Steps to an Ecology of Mind. Chandler.

Berlyne, D.E. (1960) Conflict, arousal, and curiosity. McGraw Hill.

BRILlOUIN, L. (1964) Scientific Uncertainty and Information. Academic.

Crutchfield, J. \& Young, K. (1991) Computation at the Onset of Chaos. In W. Zurek (ed.) Complexity, Entropy and the Physics of Information (pp. 223-269), Addison.

ENGESTRÖM, Y. (1991) Activity Theory and Individual and Social Transformation. Activity Theory 7/8: 6-17.

FlÜCKIGER, M. \& RAUTERBERG, M. (1995) Komplexität und Messung von Komplexität. Technical Report CC-4-95. Zürich: Institut für Arbeitspsychologie an der ETH.

FestingeR, L.A. (1957) A theory of cognitive dissonance. Stanford University Press.

FREY, D. (1981) Informationssuche und Informationsbewertung bei Entscheidungen. Huber.

GenRICH, H.J., LAUTENBACH, K. \& Thiagarajan, P.S. (1980) Elements of general net theory. In Lecture Notes in Computer Science (vol. 84 "Net Theory and Applications", pp. 21-163). Springer.

GRASSBERGER, P. (1986) Toward a quantitative theory of selfgenerated complexity. International Journal of Theoretical Physics 25(9): 907-938.

HACKER, W. (1986) Arbeitspsychologie. Huber.

HACKER, W. (1987) Software-Gestaltung als Arbeitsgestaltung. In K.-P. Fähnrich (ed.) Software-Ergonomie. State of the Art 5 (pp. 29-42). Oldenbourg.

HACKER, W. (1994) Action regulation theory and occupational psychology. Review of German empirical research since 1987. The German Journal of Psychology 18(2): 91-120.

HARTLEY, R.V.L. (1928) Transmission of information. Bell System Technical Journal, 7(3): 535-563.

HELLPACH, W. (1922) Sozialpsychologische Analyse des betriebstechnischen Tatbestandes 'Gruppenfabrikation'. In R. Lang und W. Hellpach (eds.) Gruppenfabrikation (pp. 5186). Springer.

HuNT, J.M.V. (1963) Motivation inherent in information processing and action. In: O.J. Harvey (ed.) Motivation and social interaction: cognitive determinants. Roland.
KoRnWACHS, K. \& JACOBY, K. (1996, eds.) Information new questions to a multidisziplinary concept. Akademie,

LEONTYEV, A.N. (1978) Activity, consciousness, and personality. Prentice Hall.

NeISSER, U. (1976) Cognition and Reality. Freeman.

Peterson, S.J. (1981) Petri net theory and the modeling of systems. Prentice Hall.

Rasmussen, J. (1986) Information Processing and HumanMachine Interaction. North-Holland.

RAUTERBERG, M. (1992) A method of a quantitative measurement of cognitive complexity. In: G. van der Veer, M. Tauber, S. Bagnara, and M. Antalovits (eds.) Human-Computer Interaction: Tasks and Organization. (p. 295-307), Roma: CUD.

RAUTERBERG, M. (1993) AMME: an automatic mental model evaluation to analyze user behaviour traced in a finite, discrete state space. Ergonomics 36(11): 1369-1380.

RAUTERBERG, M. (1995a) About a framework for information and information processing of learning systems. In: E. Falkenberg, W. Hesse \& A. Olive (eds.) Information System Concepts - Towards a consolidation of views. (pp. 54-69). Chapman \&Hall.

RAUTERBERG, M. (1995b) From novice to expert decision behaviour: a qualitative modelling approach with Petri nets. In Y. Anzai, K. Ogawa \& H. Mori (Eds.) Symbiosis of Human and Artifact: Human and Social Aspects of HumanComputer Interaction. (Advances in Human Factors/ Ergonomics, Vol. 20B, pp. 449-454). Elsevier.

Rauterberg, M., Berny, P., Lordong, G., Schmid, A., ZEMP, M. \& ZÜRCHER, T. (1995c) Designing multi media user interfaces with eye recording data. In: A. Grieco, G. Molteni, E. Occhipinti \& B. Piccoli (Eds.) Work with Display Units 94. North-Holland, pp. 265-270.

ShANNON, C. (1962) The mathematical theory of communication. Urbana.

SMITH, R.P. (1981) Boredom: A Review. Human Factors 23(3): 329-340.

Streufert, S. \& Streufert, S.C. (1978) Behavior in the Complex Environment. John Wiley.

TopsøE, F. (1974) Informationstheorie. Stuttgart: Teubner.

TOMASZEwSKI, T. (1981). Struktur, Funktion und Steuerungsmechanismen menschlicher Tätigkeit. In T. Tomaszewski (ed.) Zur Psychologie der Tätigkeit (pp. 11-33). Deutscher Verlag der Wissenschaften.

TuIJNMAN, A. AND VAN DER KAMP, M. (1992, eds.) Learning Across the Lifespan: Theories, Research, Policies. Pergamon.

Ulich, E., Rauterberg, M., Moll, T., Greutmann, T. \& STROHM, O. (1991) Task orientation and user-oriented dialog design. International Journal of Human-Computer Interaction 3(2): 117-144.

VöLZ, H. (1991) Grundlagen der Information. Akademie.

Voss, H.-G. \& Keller, H. (1981, eds.) Neugierforschung: Grundlagen, Theorien, Anwendungen. Beltz.

WeinerT, F.E. \& Kluwe, R.H. (1984, eds.) Metakognition, Motivation und Lernen. Kohlhammer.

WEIZsÄCKER VON, E. (1974) Erstmaligkeit und Bestätigung als Komponenten der pragmatischen Information. In E. von Weizsäcker (ed.) Offene Systeme, Band I. Beiträge zur Zeitstruktur von Information, Entropie und Evolution. Klett.

YERKES, R.M. \& Dodson, J.D. (1908) The relation of strength of stimulus to rapidity of habit-formation. Journal of Comparative Neurology of Psychology 18: 459-482.

ZUCKER, F. (1974) Information, Entropie, Komplementarität und Zeit. In E. von Weizsäcker (ed.): Offene Systeme, Band I. Beiträge zur Zeitstruktur von Information, Entropie und Evolution. Klett.

Zurek, W. (1991, ed.) Complexity, Entropy and the Physics of Information. Addison-Wesley 


\section{IEEE International Conference on Systems, Man and Cybernetics}

\section{Information \\ Intelligence \\ and Systems}

Beijing, China

October 14-17, 1996

Copyright and Reprint Permission: Abstracting is permitted with credit to the source. Libraries are permitted to photocopy beyound the limit of U.S. copyright law for private use of patrons those articles in this volume that carry a code at the bottom of the first page, provided the pre-copy fee indicated in the code is paid through Copyright Clearance Center, 222 Rosewood Drive, Danvers, MA 01923. For other copying, reprint or publication permission, write to IEEE Copyrights Manager, IEEE Service Center, 445 Hoes Lane, P.O. Box 1331, Piscataway, NJ 08855-1331. All rights reserved. Copyright ${ }^{\complement} 1996$ by the Institute of Electrical and Electronics Engineers, Inc. 